\title{
Models of the Response of Foliar Parasites to the Combined Effects of Temperature and Duration of Wetness
}

\author{
James A. Duthie
}

Department of Plant Pathology, Wes Watkins Agricultural Research and Extension Center, Oklahoma State University, Lane 74555. Accepted for publication 28 July 1997.

A central goal of botanical epidemiology is to understand the mechanisms by which the abundance of plant parasites is regulated. In a susceptible crop, the increase of a foliar parasite during a growing season often is determined primarily by weather factors, particularly duration of wetness and air temperature (40). Consequently, the effects of these factors on foliar parasites have been investigated extensively and reviewed $(7,12,28,33,40,54,65)$.

In many experimental studies $(1-5,10,11,13,15-17,20-22,24-$ $26,30,34,35,42,43,46,51,55-57,60-63)$, wetness duration and temperature are manipulated under controlled conditions to evaluate their effects. Variation in some measure of the parasite's response, such as rate of sporulation or germination, infection efficiency, latent period, lesion density, disease incidence, or disease severity, is assessed. Mean levels of the response variable may be compared among levels of the independent variables graphically $(1,46$, $55)$ or by analysis of variance procedures $(10,15,35)$. More often, the response surface is described by fitting an equation by ordinary least squares methods.

A second- or third-order polynomial equation can describe the response to combined effects of wetness duration and constant temperature $(3-5,20-22,25,26,51,60)$. To simplify the relationship, reduce heteroscedasticity, or normalize the data (53), the response variable $(13,30,60)$ or one or more of the independent variables $(26,63)$ may be transformed before fitting the equation. However, many parameters often must be estimated to characterize the response adequately $(15,50)$, partly because the structure of polynomial equations does not reflect prior knowledge of the response. Furthermore, some characteristics of the effect of duration of wetness and air temperature, such as an upper limit on the response, are described poorly by polynomial equations. The biological significance of parameter estimates from polynomial descriptions of the response is not readily assessed (57). Consequently, polynomial models contribute little to the understanding of the underlying processes. For similar reasons, mechanistic models are critical components of investigations of the dynamics of parasite populations in space $(8,14,23,29,45,47,49,68)$, time $(14,27,37,41,44,56$, $64,66)$, and space and time $(9,14,36)$. Such processes are rarely described by polynomial equations (14).

Intrinsically nonlinear models of the combined effects of wetness duration and temperature have been discussed previously (31, 32,57). Current models reflect prior information regarding the effect of wetness duration or temperature but not both. In several studies $(13,15,30,34,46,50,57)$, a nonlinear equation characterizes the component of the response due to wetness duration, but one or more polynomial equations describe the temperature response.

Corresponding author: J. A. Duthie; E-mail address: jduthie-okstate@lane-ag.org

Publication no. P-1997-0829-010

(C) 1997 The American Phytopathological Society
Nonlinear descriptions of the component of the response due to temperature are less common. Empirical data are poorly described when a nonlinear equation characterizes the temperature response, but a simple power term characterizes the response to wetness duration $(13,30)$.

In this article, the development of intrinsically nonlinear models of the effects of wetness duration and temperature that incorporate prior information regarding each of the two constituent processes is described. A new method of characterizing the component of the response due to temperature is proposed. The relationship between the proposed models and previous models of the response to wetness duration and temperature is analyzed. Preliminary reports are available $(18,19)$.

\section{MODEL DEVELOPMENT}

Except where noted, each of the following models is based on the assumptions that the response of the parasite (i) increases monotonically with duration of wetness, (ii) tends to an upper limit when the period of wetness is prolonged, (iii) decreases from a maximum as temperature decreases or increases from the optimum, and (iv) is negligible when the period of wetness is brief or when the temperature is extreme. These assumptions are well supported by many investigations of disparate foliar parasites (1$5,10,11,13,15-17,20-22,24-26,30,34,35,42,43,46,51,55-57,60-63)$. In each equation, lower- and uppercase letters represent variables and parameters, respectively. However, the same uppercase letter in different equations may represent unrelated parameters. Unless otherwise specified, each parameter has a constant, positive value.

The response $\left(y_{w}\right)$ to duration of wetness $(w)$ is described by a Weibull equation (52) of the form

$$
y_{w}=f(w)=A\left(1-\exp \left\{-[B(w-C)]^{D}\right\}\right)
$$

which is defined when $w>C$. Features of the response characterized by each parameter in equation 1 are summarized in Table 1 and illustrated in Figure 1. The response increases to an upper limit of $A$ (Fig. 1A) when $w$ is large, at an intrinsic rate of $B$ (Fig. 1B), from a lower limit of $y_{w}=0$ at $w=C$ (Fig. 1C). The location of the point of inflection is determined by $D$ (Fig. 1D). The use of the Weibull equation to describe temporal dynamics of disease has been reviewed $(14,44)$.

The response $\left(y_{t}\right)$ to constant air temperature $(t)$ is described by

$$
y_{t}=f(t)=E^{\prime}\{\exp [(t-F) G /(H+1)]\} /\{1+\exp [(t-F) G]\}
$$

in which $E^{\prime}$ is calculated by

$$
E^{\prime}=E[(H+1) / H] H^{1 /(H+1)}
$$

Features of the response curve characterized by each parameter in equation 2 are summarized in Table 2 and illustrated in Figure 2. The equation defines a unimodal curve in which the response declines from a maximum value of $E$ (Fig. 2A) and approaches a 
lower limit of 0 as temperature increases or decreases from the optimum. The optimum temperature (Fig. 2B) is calculated by

$$
t_{\mathrm{opt}}=F-(1 / G) \ln (H)
$$

The intrinsic rate of decline from the maximum value is proportional to the magnitude of $G(G>0)$ (Fig. 2C). The degree of asymmetry in the temperature response is characterized by $H(H>0)$. When $H=1$, the curve is symmetrical about $t_{\mathrm{opt}}$, and $t_{\mathrm{opt}}=F$ (Fig. 2D). When $H>1$ or $<1$, the curve is skewed negatively or positively, respectively. Previous descriptions of biological responses to temperature based on equation 2 were not found.

Models of the response ( $y$ ) to combined effects of $w$ and $t$ are defined by equations of the form

$$
y=f(w, t)
$$

In each model, the magnitude of the effect of wetness is assumed to depend on temperature. In one model, temperature influences

TABLE 1 . Summary of the features of equation $1^{\text {a }}$, which describes the response of a foliar parasite population to duration of wetness

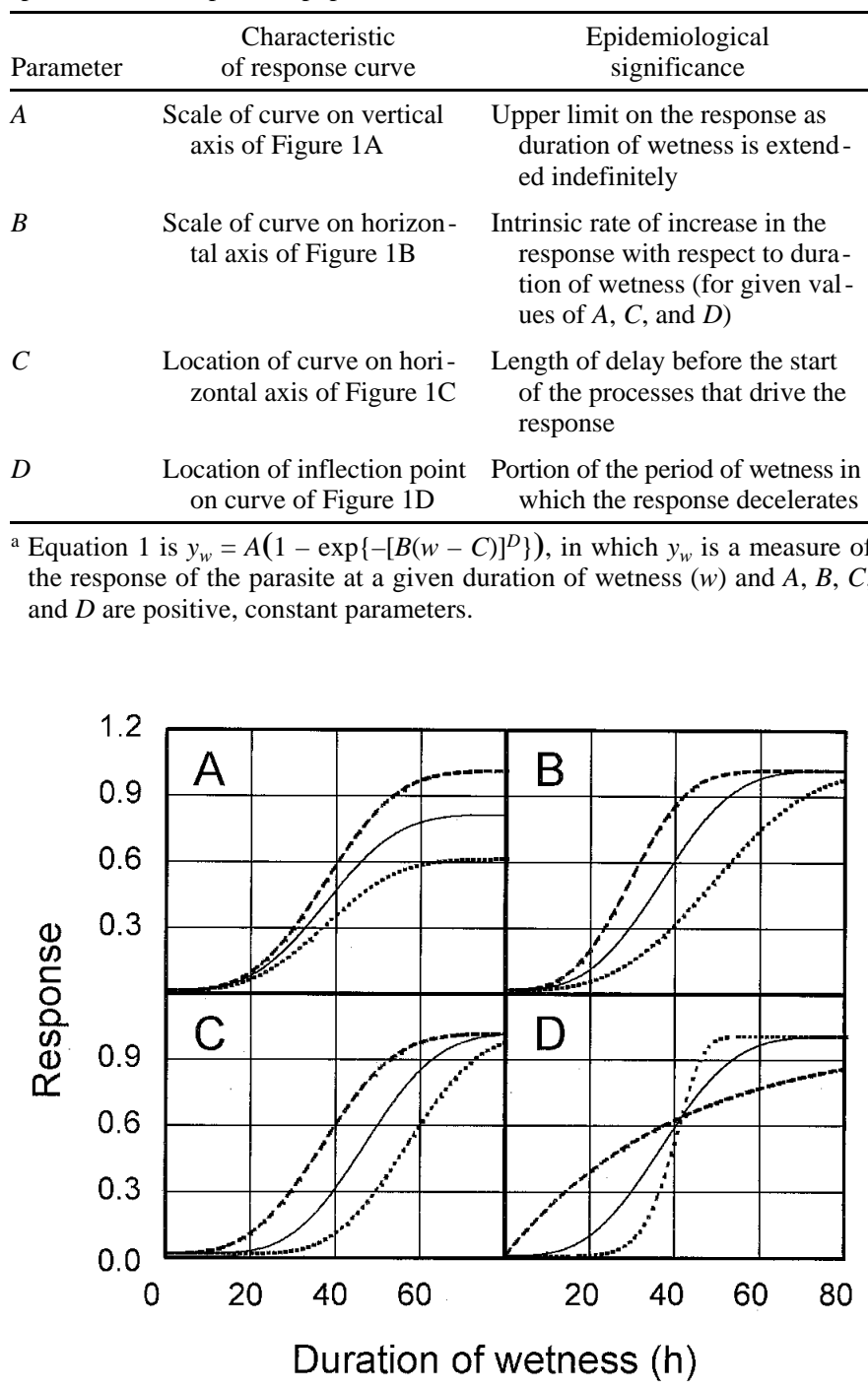

Fig. 1. Response $\left(y_{w}\right)$ of a foliar parasite population to duration of wetness $(w)$, as described by $y_{w}=A\left(1-\exp \{-[B(w-C)]\}^{D}\right)$. In A through D, parameters $A, B, C$, and $D$ have values of $1.0,0.025,0$, and 3.2 , respectively, except as follows: $\mathbf{A}, A=1.0$ (dashed line), $A=0.8$ (solid line), and $A=0.6$ (dotted line); $\mathbf{B}, B=0.02$ (dashed line), $B=0.025$ (solid line), and $B=0.030$ (dotted line); $\mathbf{C}, C=0.0$ (dashed line), $C=10$ (solid line), and $C=20$ (dotted line); and $\mathbf{D}, D=1.0$ (dashed line), $D=3.2$ (solid line), and $D=8.0$ (dotted line). The response is defined only when wetness duration is greater than the value of $C$. the upper limit on the response, which is approached as the period of wetness is extended. The limit is greatest when temperature is optimal. The limit is reduced successively as temperature increases or decreases from the optimum. This effect is characterized by allowing parameter $A$ to vary with temperature. Combined effects of $w$ and $t$ are represented by a modified version of equation 1 in which $A$ is a function of $t$. Substituting $A$ in equation 1 gives

$$
f(w, t)=f(t) \cdot\left(1-\exp \{-[B(w-C)]\}^{D}\right)
$$

in which $f(t)$ is calculated by equation 2 . Thus, in equation 3.1, equation 2 characterizes the upper limit on the response as wetness duration is extended. Parameter $E$ of equation 2.1 characterizes the upper limit after long wetness periods at the optimum temperature.

In a second model, temperature affects the intrinsic rate of increase of the response to wetness duration. The intrinsic rate is greatest when temperature is optimal and is reduced successively as temperature becomes increasingly suboptimal. Combined ef-

\begin{tabular}{|c|c|c|}
\hline Parameter & $\begin{array}{l}\text { Characteristic } \\
\text { of response curve }\end{array}$ & $\begin{array}{l}\text { Epidemiological } \\
\text { significance }\end{array}$ \\
\hline$E$ & $\begin{array}{l}\text { Scale of curve on vertical } \\
\text { axis of Figure } 2 \mathrm{~A}\end{array}$ & $\begin{array}{l}\text { Maximum response that occurs at } \\
\text { the optimum temperature }\end{array}$ \\
\hline$F$ & $\begin{array}{l}\text { Location of curve on hori- } \\
\text { zontal axis of Figure 2B }\end{array}$ & $\begin{array}{l}\text { Directly proportional to the opti - } \\
\text { mum temperature }\end{array}$ \\
\hline$G$ & $\begin{array}{l}\text { Scale of curve on hori- } \\
\text { zontal axis of } \\
\text { Figure } 2 \mathrm{C}\end{array}$ & $\begin{array}{l}\text { Intrinsic rate of decline from the } \\
\text { maximum as temperature de- } \\
\text { viates from the optimum (for } \\
\text { given values of } E, F \text {, and } G \text { ) }\end{array}$ \\
\hline$H$ & $\begin{array}{l}\text { Degree of asymmetry in } \\
\text { curve of Figure 2D }\end{array}$ & $\begin{array}{l}\text { Difference as temperature increases } \\
\text { or decreases from the optimum } \\
\text { in the rate of acceleration in the } \\
\text { decline from the maximum }\end{array}$ \\
\hline
\end{tabular}

TABLE 2. Summary of features of equation $2^{\mathrm{a}}$, which describes the response of a foliar parasite population to temperature

a Equation 2 is $y_{t}=E^{\prime}\{\exp [(t-F) G /(H+1)]\} /\{1+\exp [(t-F) G]\}$, in which $y_{t}$ is a measure of the response of the parasite at a given temperature $(t), E^{\prime}$ is calculated by $E[(H+1) / H] H^{1 /(H+1)}$, and $E, F, G$, and $H$ are constant parameters.

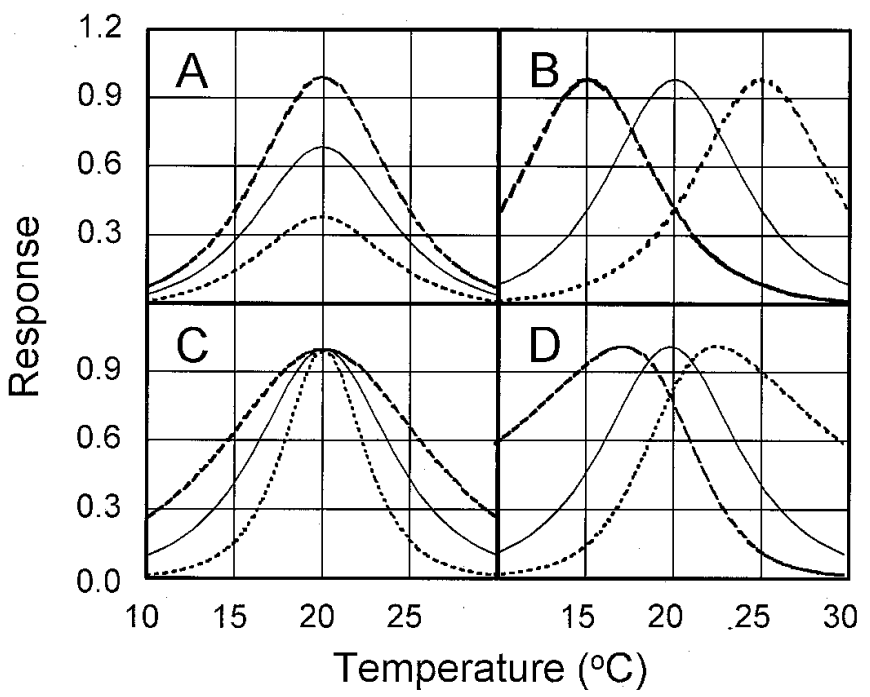

Fig. 2. Response $\left(y_{t}\right)$ of a foliar parasite population to temperature $(t)$, as described by $y_{t}=E^{\prime}\{\exp [(t-F) G /(H+1)]\} /\{1+\exp [(t-F) G]\}$, in which $E^{\prime}=$ $E[(H+1) / H] H^{1 /(H+1)}$. In A through D, parameters $E, F, G$, and $H$ have values of 1.0, 20, 0.6, and 1.0, respectively, except as follows: $\mathbf{A}, E=1.0$ (dashed line), $E=0.7$ (solid line), and $E=0.4$ (dotted line); $\mathbf{B}, F=15$ (dashed line), $F=20$ (solid line), and $F=25$ (dotted line); $\mathbf{C}, G=0.4$ (dashed line), $G=$ 0.6 (solid line), and $G=1.0$ (dotted line); and $\mathbf{D}, H=5.0$ (dashed line), $H=$ 1.0 (solid line), and $H=0.2$ (dotted line). 
fects of $w$ and $t$ are characterized by substituting $B$ in equation 1 with a description of the response to temperature:

$$
f(w, t)=A\left\{1-\exp [-f(t) \cdot(w-C)]^{D}\right\}
$$

in which $f(t)$ is given by equation 2 . Thus, in equation 3.2 , equation 2 characterizes the intrinsic rate of increase in response to duration of wetness. Parameter $E$ of equation 2.1 characterizes the intrinsic rate at the optimum temperature.

Equations 3.1 (Fig. 3) and 3.2 (Fig. 4) are sufficiently flexible to generate a range of types of response surfaces. With appropriate parameter values, the surfaces qualitatively resemble the empirical response surfaces described in many experimental investigations of combined effects of duration of wetness and constant temperature $(1-5,10,11,13,15-17,20-22,24-26,30,34,35,42,43,46,51,55-$ $57,60-63)$. Features of the response surface that are determined by each parameter of equation 3.1 are illustrated in Figure 3 and discussed below. Features of surfaces generated by equation 3.2 are comparable (Fig. 4).

The intrinsic-rate parameter, $B(0<B<1)$, is proportional to the rate of increase in response to wetness duration (compare Fig. 3A

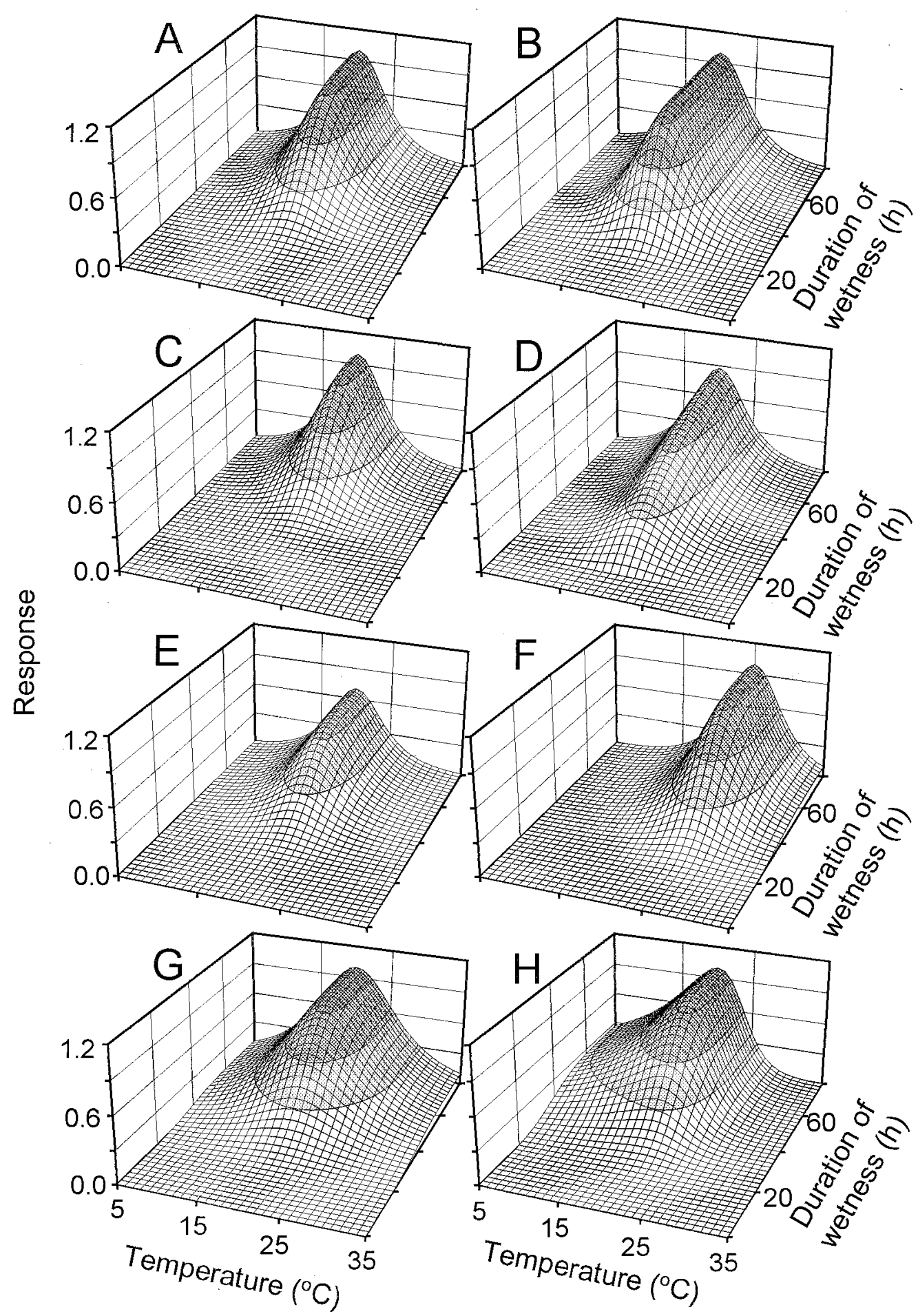

Fig. 3. Response $(y)$ of a foliar parasite population to the combined effects of duration of wetness $(w)$ and temperature $(t)$, as described by the equation $y=f(t) \cdot(1-$ $\left.\exp \{-[B(w-C)]\}^{D}\right)$, in which $f(t)=E^{\prime}\{\exp [(t-F) G]\} /\{1+\exp [(t-F) G(H+1)]\}$ and $E^{\prime}=E[(H+1) / H] H^{1 /(H+1)}$. In A through $\mathbf{H}, \operatorname{parameters} B, C, D, E, F, G$, and $H$ have values of $0.03,10,3.2,1.0,20,0.5$, and 1.0 , respectively, except as follows: $\mathbf{B}, B=0.05 ; \mathbf{C}, C=20 ; \mathbf{D}, D=1.0 ; \mathbf{E}, E=0.7 ; \mathbf{F}, F=25 ; \mathbf{G}, G=0.4$; and $\mathbf{H}, F=22.7$ and $H=5.0$. The response is undefined when wetness duration is less than the value of $C$. 
and $\mathrm{B}$ ) for given values of the remaining parameters. The lag parameter, $C(C>0)$, characterizes the length of the delay in the response to wetness. Thus, $C$ locates the response surface on the wetness-duration axis (compare Fig. 3A and C). An analogous lag parameter has been used in descriptions of response to wetness duration based on a Gompertz (57) or monomolecular equation (24).

Equation 3.1 implies that the response increases after each successive period of wetness. However, the absolute rate of increase varies over the range of the response. The acceleration parameter, $D(D>0)$, characterizes variation in the absolute rate. For ex- ample, if $D>1$, the response at first accelerates (i.e., the absolute rate increases) and later decelerates. The curve inflects when the response is approximately one-half the upper limit when $D=3.2$ (14). Values of $D$ greater than 3.2 or less than 3.2 imply a shorter or longer period of deceleration, respectively. When $D \leq 1$ (Fig. $3 \mathrm{D})$, the period of acceleration is absent, and the response decelerates over the entire range. Thus, $D$ is proportional to $d^{2} y / d w^{2}$, the second derivative with respect to wetness, whereas $B$ is proportional to $d y / d w$, the first derivative. Graphically, $D$ locates the point of inflection on the response axis (compare Fig. 3A and D),

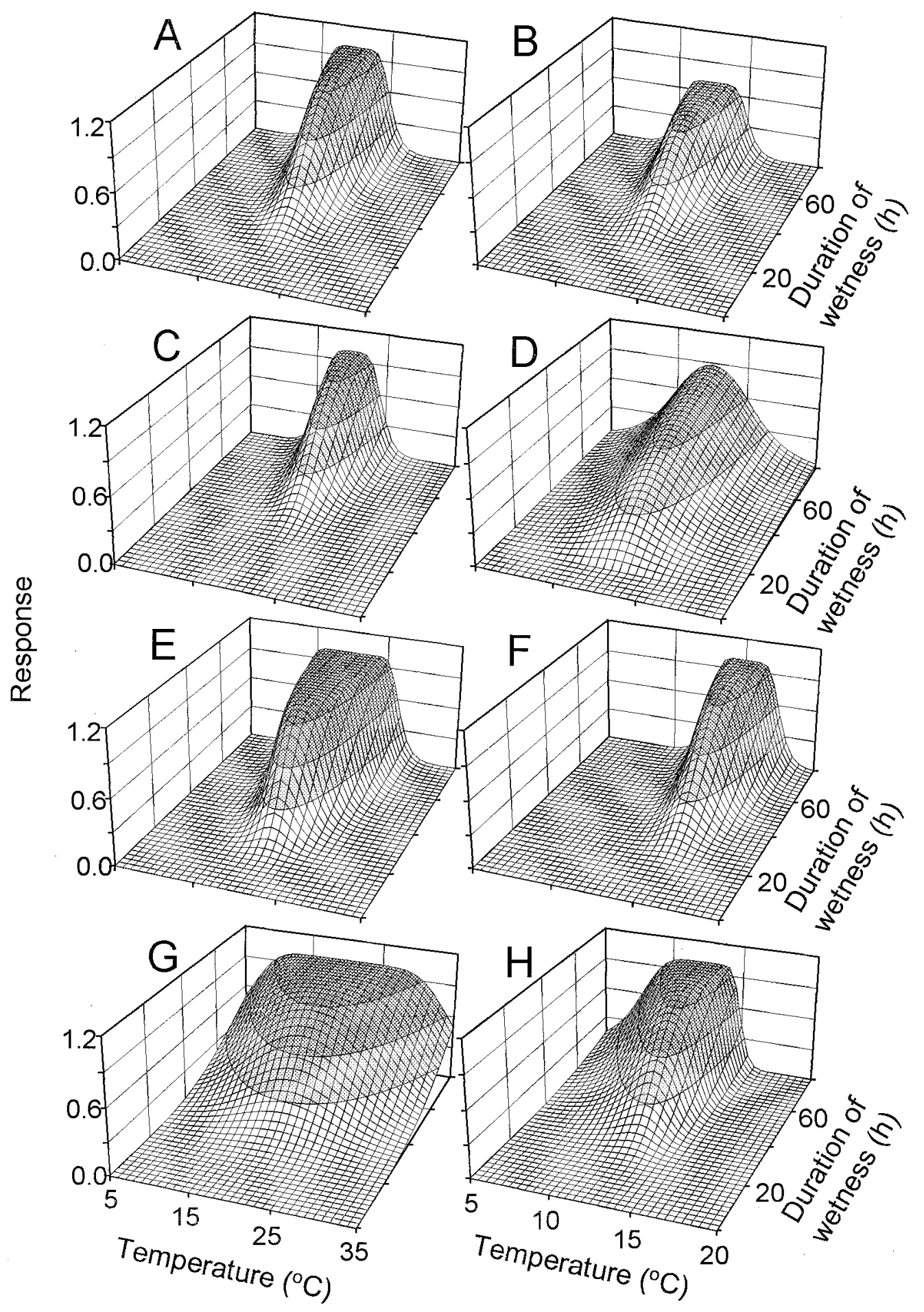

Fig. 4. Response $(y)$ of a foliar parasite population to the combined effects of duration of wetness $(w)$ and temperature $(t)$, as described by the equation $y=A(1-$ $\left.\exp \{-[f(t) \cdot(w-C)]\}^{D}\right)$, in which $f(t)=E^{\prime}\{\exp [(t-F) G]\} /\{1+\exp [(t-F) G(H+1)]\}$ and $E^{\prime}=E[(H+1) / H] H^{1 /(H+1)}$. In A through $\mathbf{H}$, parameters $A, C, D, E, F$, $G$, and $H$ have values of 1.0,10,3.2, 0.03, 20, 0.5, and 1.0, respectively, except as follows: $\mathbf{B}, A=0.7 ; \mathbf{C}, C=20 ; \mathbf{D}, D=1.0 ; \mathbf{E}, E=0.05 ; \mathbf{F}, F=25 ; \mathbf{G}, G=$ 0.2 ; and $\mathbf{H}, F=22.7$ and $H=5.0$. The response is undefined when wetness duration is less than the value of $C$. 
whereas $B$ characterizes the scale of the response surface along the wetness-duration axis (compare Fig. 3A and B).

Because the response tends to a lower limit of 0 at extreme temperatures, the response varies within a range of $0<y<E$. Thus, the upper limit parameter, $E(E>0)$, determines the scale of the response on the vertical axis. When $E$ is reduced from $E=1$ (Fig. 3A) to $E=0.7$ (Fig. 3E), the response surfaces ascend to different upper limits but are otherwise similar. Parameter $F$, which may vary between negative and positive infinity, locates the response surface on the temperature axis. For example, the surface is translated on the temperature axis as $F$ varies from 20 (Fig. 3A) to 25 (Fig. 3F).

The intrinsic-rate parameter, $G(G>0)$, determines for given values of the remaining parameters the rate of decline in the response as temperature increases or decreases from the optimum. Thus, the scale of the response on the temperature axis increases when the value of $G$ is reduced from 0.3 (Fig. 3A) to 0.1 (Fig. $3 \mathrm{G})$. Asymmetry in the response surface is characterized by $H(H>0)$. When $H<1,=1$, or $>1$, the surface is skewed positively, symmetrical (Fig. 3A), or skewed negatively (Fig. 3H), respectively.

Seven parameters are defined explicitly in equations 3.1 and 3.2. To obtain reliable estimates of each parameter, measurements at a minimum of 20 to 30 combinations of wetness duration and temperature are likely to be needed. In some studies, these equations may be overparameterized; insufficient data may be available to estimate each parameter precisely. However, a reduced form of one of the equations may be adequate. Each equation is simplified readily by fixing values of selected parameters based on prior knowledge of the response. Reduced forms of equation 3.1 are discussed briefly. Equation 3.2 may be simplified similarly.

Growth-curve equations that lack an explicit lag parameter imply that the parasite responds more or less immediately, although possibly at low levels, to a period of wetness. Thus, $C$ often is assumed to be negligible $(C=0)$. However, the lag parameter also may have some other value (57). Similarly, the value of $D$ may be fixed, possibly at integer values of $1,2,3$, or 4, based on prior knowledge of the point at which the response begins to decelerate. The monomolecular, Gompertz, and logistic equations imply analogous assumptions $(14,44)$.

The value of $E$ of equation 3.1 can be fixed if the upper limit on the response is known. For example, it may be appropriate to set $E=1$ if disease severity is measured on a scale of 0 to 1.0. A similar assumption is implied by forms of the monomolecular, Gompertz, or logistic equation that lack an explicit upper asymptote parameter. The temperature response of many microorganisms (6), including many plant parasites $(2,46)$, is skewed negatively. However, under some conditions asymmetry in the temperature response may be negligible. In some studies, the response may not be measured at high temperatures if under field conditions wetness is rare when temperatures are high. Thus, asymmetry may be disregarded. It follows that $H=1, t_{\mathrm{opt}}=F, E^{\prime}=2 E$, and

$$
\begin{aligned}
y_{t}=f(t) & =2 E /\{\exp [-(t-F) G / 2]+\exp [(t-F) G / 2]\} \\
& =E \cdot \operatorname{sech}[(t-F) G / 2] \\
& =E / \cosh [(t-F) G / 2]
\end{aligned}
$$

in which sech is the hyperbolic secant and cosh is the hyperbolic cosine. Based on the additional assumptions described above, the full model of the response defined by equation 3.1 reduces to a three-parameter model of the form

$$
f(w, t)=\left[1-\exp (-B w)^{3.2}\right] / \cosh [(t-F) G / 2]
$$

Parameters of equation 5 are defined as in equations 1 and 2, except that values of $C, D, E$, and $H$ are fixed at $0,3.2,1$, and 1 , respectively.

\section{ALTERNATIVE MODELS}

Models similar to those defined by equations 3.1 and 3.2 can be constructed readily from alternative descriptions of the constituent processes. The response to wetness duration often is described by a growth-curve equation, such as the monomolecular (24), Gompertz $(57,61,62)$, logistic $(13,15,21,30)$, and Richard's $(17,50)$ equations. The advantage of the Weibull equation is that no parameter is required to estimate the y-intercept. The absence of a response at the beginning of the wetness period is assumed. Furthermore, in describing disease progress, the parameters of the Weibull equation may be estimated more readily than the parameters of analogous forms of growth-curve equations (44). Whether Weibull parameters are more easily estimated in the context of the response to wetness duration and temperature remains to be determined.

Equation 1 implies that the response to wetness duration decelerates at some point. In a simpler model, the response accelerates overall values of wetness duration, as in

$$
f(w)=A\{\exp [B(w-C)]-1\}
$$

in which $0<A<1,0<B<1$, and $C>0$, or

$$
f(w)=A(w-C)^{B}
$$

in which $0<A<1, B>1$, and $C>0$. A response to combined effects of duration of wetness and temperature could be described by substituting in equation 6 or 7 either parameter $A$ or $B$ with a suitable description of the temperature response (equation 2). Grove et al. (30) evaluated the fit of an equation similar to equation 7 in which the temperature response was described by equation 10 (described below).

Equation 2 may be reparameterized, such that $G$ and $H$ together characterize both the skewness in the temperature response and the intrinsic rate of the temperature response. In the equation

$$
y_{t}=f(t)=E^{\prime}\{\exp [(t-F) G]\} /\{1+\exp [(t-F)(G+H)]\}
$$

$E^{\prime}$ is given by

$$
E^{\prime}=E(G+H) /\left[H(G / H)^{G /(G+H)}\right]
$$

and the optimum temperature is given by

$$
t_{\text {opt }}=F+[\ln (G / H)] /(G+H)
$$

Parameters $E$ and $F$ in equation 8 are defined as in equation 2, but the ratio $G / H$ characterizes skewness. When $G / H<1,=1$, or $>1$, respectively, the curve is skewed negatively, symmetrical, or skewed positively. The intrinsic rate of the temperature response is proportional to the magnitudes of $G$ and $H$.

A simpler model of a symmetrical temperature response is defined by

$$
y_{t}=f(t)=E /\left\{\exp \left[(t-F)^{2} G\right]\right\}
$$

in which $E$ is the maximum response when the temperature is optimal, $F$ is the optimal temperature, and $G$ is the intrinsic rate of decline in the response from the maximum response. Equation 9 is based on the normal probability density function. Parameters $F$ and $1 / G$ are analogous to the mean and variance of the normal distribution, respectively. Previous descriptions of biological responses to temperature by equation 4,8 , or 9 was not found.

Other equations for describing the response of plant parasites to temperature have been reviewed $(28,31)$. One equation, based on the beta probability density function, has the form

$$
y_{t}=f(t)=E^{\prime} t^{\prime} G\left(1-t^{\prime}\right)^{H}
$$

in which $E^{\prime}$ is computed by

$$
E^{\prime}=E\left[(G+H)^{G+H}\right] /\left(G^{G} H^{H}\right)
$$

(2). Values of temperature are scaled between 0 and 1 by the transformation

$$
t^{\prime}=100\left(t-F_{1}\right) /\left(F_{2}-F_{1}\right)
$$

Parameters $E, G$, and $H$ of equation 10 are analogous to parameters $E, G$, and $H$, respectively, of equation 8 . In equation $10, E$ characterizes the maximum response level, and $G$ and $H$ together 
determine the intrinsic rate of decline from the maximum. When $G / H=1$ or $<1$ the response curve is symmetrical or skewed negatively, respectively. Parameters $F_{1}$ and $F_{2}$ characterize the minimum and maximum temperatures, respectively, at which the parasite responds and, thus, locate the response on the temperature axis.

Combined effects of wetness duration and temperature have been analyzed by an expression that is similar to equation 10 , in which the response to wetness is described by a power function in the form of equation $7(13,15,30)$. Equations 2, 8, and 9 require fewer parameters to describe the temperature response because the location of the response on the temperature axis is defined by a single parameter. More mechanistic descriptions of a temperature response may be derived from thermodynamic analyses of enzyme reaction rates (58) or demographic analyses (67).

The response of plant parasites to temperature has been described empirically by a modified polynomial equation of the form

$$
y_{t}=f(t)=E \cdot \sin ^{2}\left(G_{1} t^{\prime 0}+G_{2} t^{\prime 1}+G_{3} H t^{\prime 2}+G_{4} t^{3}\right)
$$

in which values of temperature are scaled as in equation 10.2 (59). The biological significance of the polynomial coefficients $G_{1}, G_{2}$, $G_{3}$, and $G_{4}$ is unclear. Furthermore, many parameters are needed to describe the response. Nevertheless, a similar model can describe combined effects of duration of wetness and temperature (30). Similarly, a parabolic equation of the form

$$
y_{t}=f(t)=E t^{G_{1}} G_{2}{ }^{{ }^{G_{3}}}
$$

can describe the effect of temperature on an upper limit parameter (50), but the significance of parameters $G_{1}, G_{2}$, and $G_{3}$ is obscure.

\section{COMPARISON OF EQUATIONS 3.1 AND 3.2}

Equations 3.1 and 3.2 each characterize the response to wetness duration and temperature with seven, analogous parameters. The models defined by these equations share several common features. In each model, an upper limit on the response is approached when the wetness period is prolonged. The response is small, undefined, or negligible when the period of wetness is brief or when the temperature is extreme. However, the models differ fundamentally. Equation 3.1 implies that temperature influences the upper limit on the response to wetness duration but not the intrinsic rate of the response; equation 3.2 implies the converse. Consequently, the two models describe very different responses to extended wetness periods.

In equation 3.1, the response to wetness duration remains temperature dependent regardless of the length of the wetness period. After a very long period of wetness, variation in the response is described more or less completely by equation 2.1. At extreme temperatures, the response is undetectable even when wetness is prolonged. In contrast, equation 3.2 implies that the response becomes less dependent on temperature as the wetness period is extended. Eventually the response approaches the same upper limit at all temperatures. This difference between the models defined by equations 3.1 and 3.2 can be shown graphically. In Figure 3B (equation 3.1), the response to temperature is constant when the period of wetness is within the range of 40 to $80 \mathrm{~h}$. In Figure 4E (equation 3.2), the response approaches an upper limit at an increasingly broad range of temperatures when the period of wetness is within the range of 40 to $80 \mathrm{~h}$.

The distinct mechanisms implied by equation 3.1 and 3.2 emphasize the need for a better understanding of the combined effects of duration of wetness and temperature on the response of foliar parasites. Further work is needed to evaluate, for specific host-parasite interactions, the temperature dependence of the response to wetness duration. However, the primary purpose of many analyses is simply to describe precisely the response to the combined effects of wetness duration and temperature. If the response clearly becomes limited at suboptimal temperatures (13 [Fig. 1A],
15 [Fig. 1A and B]), then a model defined by equation 3.1 may be superior. However, in several studies (60 [Fig. 1], 13 [Figs. 1B, $2 \mathrm{~A}$ and $2 \mathrm{~B}$, and $3 \mathrm{~A}$ and $3 \mathrm{~B}]$ ), the response to wetness is concave upward and does not inflect at suboptimal temperatures. The upper limit is apparent only when the temperature is close to the optimum. Under these conditions, a model similar to equation 3.2 would seem likely to provide a better fit than equation 3.1.

A simple simulation shows that the response surfaces defined by equation 3.1 and 3.2 may be similar numerically, even though the equations differ analytically. For example, if one response conforms to equation 3.1, as illustrated in Figure 3A (i.e., $B=0.03$, $C=10, D=3.2, E=1.0, F=20, G=0.5$, and $H=1.0$ in equation 3.1 ), and that a second response conforms to equation 3.2, as illustrated in Figure 4A (i.e., $A=1.0, C=10, D=3.2, E=0.03$, $F=20, G=0.5$, and $H=1.0$ in equation 3.2), then measurements made on each response after $12,18,24,30,36,42,48$, and $54 \mathrm{~h}$ of wetness at each of $12,16,20,24,28$, and $32^{\circ} \mathrm{C}$ are highly correlated $(r=0.94)$. Thus, some responses to wetness duration and temperature may be described adequately by either equation 3.1 or 3.2. Consequently, temperature dependence in the intrinsic rate and upper limit are not necessarily distinguished by comparing goodness-of-fit of equations to empirical data. In further research, the nature of the underlying processes should be evaluated directly, possibly by investigating responses to long periods of wetness at extreme temperatures.

More complex models of the overall response have been based on the temperature dependence of two $(13,15,30,43,46,57)$ or more (34) of the parameters that characterize the response to wetness duration. The overall response of several parasites has been well described by models in which both the upper limit and intrinsic rate of the wetness response vary with temperature $(13,15,30,34$, $43,46,57)$. In these studies, variation with temperature is characterized by one or more polynomial equations, but a more mechanistic equation, such as equation 3.1 or 3.2 , also may be suitable.

An empirical comparison of simple models and more complex analogues is needed. Increasing the number of temperature-dependent parameters often will improve the fit of a model to empirical data. However, the resulting complexity of the models has theoretical and practical disadvantages. The complex hypotheses implicit in these models are unnecessary if simpler hypotheses are sufficient to account for the overall response. For models in which both the upper limit and intrinsic rate of the wetness responses vary, the two processes may not be estimable independently. Thus, when parameters are estimated iteratively, the estimates may be highly correlated or the algorithm may not converge on a solution. The simple simulation described above suggests that empirical data may be insufficient to distinguish simple models in which the temperature-dependent parameter differs. The description of similar empirical data would not be improved by increasing the number of temperature-dependent parameters in a model, particularly if the observed response to wetness at suboptimal temperatures does not inflect but remains concave upward over the range of wetness duration.

Complex models comprising two temperature-dependent parameters were fitted by a two-stage regression procedure (31) in several studies $(13,15,30,34,43,46,57)$. Some difficulties of parameter estimation are avoided with this approach, but the independence of the parameter estimates and standard errors on parameter estimates cannot be assessed readily $(31,50)$. Parameter estimates, correlation among parameters, and standard errors are computed more easily when simpler models, such as those defined by equations 3.1 and 3.2, are fitted directly to empirical data by least squares methods (50).

In each model discussed, temperature mediates the response to wetness duration. In an alternative construction, wetness duration might mediate the response to temperature. For example, the maximum response to temperature may depend on wetness duration. Thus, a model might be defined by equation 2 , in which variation 
in parameter $E$ is described by equation 1 . However, this model is equivalent to the model defined by equation 3.1. Other parameters of equation 2 may depend on wetness duration. Whether optimal temperature, intrinsic rate of decline in the response as temperature deviates from the optimum, or skewness in the temperature response varies with wetness duration remains to be investigated.

\section{CONCLUSIONS}

This article proposes simple models for directly evaluating the response of foliar parasites to the combined effects of duration of wetness and temperature. The models comprise novel equations for describing the component of the response due to temperature. Prior knowledge of each of the two constituent processes underlies each model. The models, therefore, are likely to provide a more parsimonious description of empirical data than previous models that wholly or in part comprise polynomial equations. The biological significance of each parameter in the proposed models is clear. Consequently, these models provide a conceptual framework for analyzing effects of wetness duration and temperature that has been lacking. In practice, the parameters in the proposed models should be estimated more easily than the parameters of previous models based on more complex hypotheses. The general structure of the models, in which the combined effects of two independent variables are characterized by describing variation in a parameter of one mechanistic equation by a second mechanistic equation, is becoming more frequent in quantitative, phytopathological analyses $(38,39,48,66)$.

The fit of the proposed models to empirical data will be addressed in a separate article. In particular, the distribution of error terms will be assessed for several foliar parasites. However, the proposed models clearly have the flexibility to describe a wide range of response surfaces. Based on the qualitative resemblance of these hypothetical surfaces to published data $(1-5,10,11,13,15-$ $17,20-22,24-26,30,34,35,42,43,46,51,55-57,60-63)$, the response of many plant parasites to the combined effects of wetness duration and temperature can be characterized suitably.

\section{ACKNOWLEDGEMENTS}

I thank C. L. Goad (Department of Statistics, Oklahoma State University) for help with the calculus.

\section{LITERATURE CITED}

1. Alderman, S. C., and Beute, M. K. 1986. Influence of temperature and moisture on germination and germ tube elongation of Cercospora arachidicola. Phytopathology 76:715-719.

2. Analytis, S. 1977. Uber die Relationzwischen biologischer Entwicklung und Temperatur phytopathogen Pilzen. Phytopathol. Z. 90:64-76.

3. Arauz, L. F., and Sutton, T. B. 1989. Temperature and wetness duration requirements for apple infection by Botryosphaeria obtusa. Phytopathology 79:440-444.

4. Arauz, L. F., and Sutton, T. B. 1989. Influence of temperature and moisture on germination of ascospores and conidia of Botryosphaeria obtusa. Phytopathology 79:667-674.

5. Arny, C. J., and Rowe, R. C. 1991. Effects of temperature and duration of wetness on spore production and infection of cucumbers by Didymella bryoniae. Phytopathology 81:206-209.

6. Atlas, R. M., and Bartha, R. 1993. Microbial Ecology. Benjamin/Cummings Publishing Co., Redwood City, CA.

7. Aust, H. J., and Hoyningen-Huene, J. 1986. Microclimate in relation to epidemics of powdery mildew. Annu. Rev. Phytopathol. 24:491-510.

8. Aylor, D. E. 1987. Deposition gradients of urediniospores of Puccinia recondita near a source. Phytopathology 77:1442-1448.

9. Aylor, D. E., and Ferrandino, F. J. 1989. Temporal and spatial development of bean rust epidemics initiated from an inoculated line source. Phytopathology 79:146-151.

10. Barbetti, M. J. 1991. Effects of temperature and humidity on diseases caused by Phoma medicaginis and Leptosphaerulina trifolii in lucerne (Medicago sativa). Plant Pathol. 40:296-301.

11. Broome, J. C., English, J. T., Marois, J. J., Latorre, B. A., and Aviles, J. C.
1995. Development of an infection model for Botrytis bunch rot of grapes based on wetness duration and temperature. Phytopathology 85: 97-102.

12. Bourke, P. M. A. 1970. Use of weather information in the prediction of plant disease epiphytotics. Annu. Rev. Phytopathol. 8:345-370.

13. Bulger, M. A., Ellis, M. A., and Madden, L. V. 1987. Influence of temperature and wetness duration on infection of strawberry flowers by Botrytis cinerea and disease incidence on fruit originating from infected flowers. Phytopathology 77:1225-1230.

14. Campbell, C. L., and Madden, L. V. 1990. Introduction to Plant Disease Epidemiology. John Wiley \& Sons, New York.

15. Carisse, O., Kushalappa, A. C., and Cloutier, D. C. 1993. Influence of temperature, leaf wetness, and high relative humidity duration on sporulation of Cercospora carotae on carrot leaves. Phytopathology 83:338-343.

16. Cohen, Y. 1977. The combined effects of temperature, leaf wetness, and inoculum concentration on the infection of cucumbers with Pseudoperonospora cubensis. Can. J. Bot. 55:1478-1487.

17. de Vallavieille-Pope, C., Huber, L., Leconte, M., and Goyeau, H. 1995. Comparative effects of temperature and interrupted wet periods on germination, penetration, and infection of Puccinia recondita $\mathrm{f}$. sp. tritici and P. striiformis on wheat seedlings. Phytopathology 85:409-415.

18. Duthie, J. A., and Damicone, J. P. 1995. A mechanistic model of the response of a foliar parasite to combined effects of temperature and duration of leaf wetness. (Abstr.) Phytopathology 85:1158.

19. Duthie, J. A., and Damicone, J. P. 1996. A mechanistic model of combined effects of temperature and duration of wetness on intensity of a foliar disease. (Abstr.) Phytopathology 86 (Suppl.):S4.

20. Eisensmith, S. P., and Jones, A. L. 1981. A model for detecting infection periods of Coccomyces hiemalis on sour cherry. Phytopathology 71:728732.

21. Elliot, V. J. 1988. Response models for conidiospore germination and germ tube elongation of Mycosphaerella fragariae as influenced by temperature and moisture. Phytopathology 78:645-650.

22. Evans, K. J., Nyquist, W. E., and Latin, R. X. 1992. A model based on temperature and leaf wetness duration for establishment of Alternaria leaf blight of muskmelon. Phytopathology 82:890-895.

23. Ferrandino, F. J., and Elmer, W. H. 1996. Septoria leaf spot lesion density on trap plants exposed at varying distances from infected tomatoes. Plant Dis. 80:1059-1062.

24. Figueroa, L., Fitt, B. D. L., Welham, J., Shaw, M. W., and McCartney, H. A. 1995. Early development of light leaf spot (Pyrenopeziza brassicae) on winter oilseed rape (Brassica napus) in relation to temperature and leaf wetness. Plant Pathol. 44:641-654.

25. Filajdic, N., and Sutton, T. B. 1992. Influence of temperature and wetness duration on infection of apple leaves and virulence of different isolates of Alternaria mali. Phytopathology 82:1279-1283.

26. Fitzell, R. D., Peak, C. M., and Darnell, R. E. 1984. A model for estimating infection levels of anthracnose disease of mango. Ann. Appl. Biol. 104:451-458.

27. Fracker, S. B. 1936. Progressive intensification of uncontrolled plantdisease outbreaks. J. Econ. Entomol. 29:923-940.

28. Friesland, H., and Schrodter, H. 1987. The analysis of weather factors in epidemiology. Pages 115-134 in: Experimental Techniques in Plant Disease Epidemiology. J. Kranz and J. Rotem, eds. Springer-Verlag, Berlin.

29. Gregory, P. H. 1968. Interpreting plant disease dispersal gradients. Annu. Rev. Phytopathol. 6:189-212.

30. Grove, G. G., Madden, L. V., Ellis, M. A., and Schmitthenner, A. F. 1985. Influence of temperature and wetness duration on infection of immature strawberry fruit by Phytophthora cactorum. Phytopathology 75:165-169.

31. Hau, B., Eisensmith, S. P., and Kranz, J. 1985. Construction of temporal models. Pages 31-65 in: Advances in Plant Pathology. Vol. 3, Mathematical Modelling of Crop Disease. C. A. Gilligan, ed. Academic Press, New York.

32. Hau, B., and Kranz, J. 1990. Mathematics and statistics for analyses in epidemiology. Pages 12-52 in: Epidemics of Plant Diseases: Mathematical Analysis and Modeling. 2nd ed. J. Kranz, ed. Springer-Verlag, New York.

33. Huber, L., and Gillespie, T. J. 1992. Modeling leaf wetness in relation to plant disease epidemiology. Annu. Rev. Phytopathol. 30:553-577.

34. Imhoff, M. W., Main, C. E., and Leonard, K. J. 1981. Effect of temperature, dew period, and age of leaves, spores, and source pustules on germination of bean rust urediospores. Phytopathology 71:577-583.

35. Jacome, L. H., and Schuh, W. 1992. Effects of leaf wetness duration and temperature on development of Black Sigatoka disease on banana infected by Mycosphaerella fijiensis var. difformis. Phytopathology 82:515520 .

36. Jeger, M. J. 1983. Analysing epidemics in time and space. Plant Pathol. 32:5-11.

37. Jeger, M. J. 1986. The potential of analytic compared with simulation approaches to modeling in plant disease epidemiology. Pages 255-281 
in: Plant Disease Epidemiology: Population Dynamics and Management, vol. 1. K. J. Leonard and W. E. Fry, eds. Macmillan Publishing Co., New York.

38. Jeger, M. J. 1987. The influence of root growth and inoculum density on the dynamics of root disease epidemics: Theoretical analysis. New Phytol. 107:459-478.

39. Johnson, K. B. 1994. Dose-response relationships and inundative biological control. Phytopathology 84:780-784.

40. Jones, A. L. 1987. Role of wet periods in predicting foliar diseases. Pages 87-100 in: Plant Disease Epidemiology: Population Dynamics and Management, vol. 1. K. J. Leonard and W. E. Fry, eds. Macmillan Publishing Co., New York.

41. Jowett, D., Browning, J. A., and Haning, B. C. 1974. Nonlinear disease progress curves. Pages 78-114 in: Epidemics of Plant Diseases: Mathematical Analysis and Modeling. J. Kranz, ed. Springer-Verlag, New York.

42. Keitt, G. W., Blodgett, E. C., Wilson, E. E., and Magie, R. O. 1937. The epidemiology and control of cherry leaf spot. Wis. Agric. Exp. Stn. Res. Bull. 132:1-118.

43. Lalancette, N., Ellis, M. A., and Madden, L. V. 1988. Development of an infection efficiency model for Plasmopara viticola on American grape based on temperature and duration of leaf wetness. Phytopathology 78: 794-800.

44. Madden, L. V., and Campbell, C. L. 1990. Nonlinear disease progress curves. Pages 181-229 in: Epidemics of Plant Diseases: Mathematical Analysis and Modeling. 2nd ed. J. Kranz, ed. Springer-Verlag, Berlin.

45. McCartney, H. A., and Fitt, B. D. L. 1985. Construction of dispersal models. Pages 107-143 in: Advances in Plant Pathology. Vol. 3, Mathematical Modelling of Crop Disease. C. A. Gilligan, ed. Academic Press, New York.

46. McRae, C. F., and Auld, B. A. 1988. The influence of environmental factors on anthracnose of Xanthium spinosum. Phytopathology 78:1182-1186.

47. Minogue, K. P. 1986. Disease gradients and the spread of disease. Pages 285-310 in: Plant Disease Epidemiology: Population Dynamics and Management, vol. 1. K. J. Leonard and W. E. Fry, eds. Macmillan Publishing Co., New York.

48. Montesinos, E., and Bonaterra, A. 1996. Dose-response models in biological control of plant pathogens: An empirical verification. Phytopathology 86:464-472.

49. Mundt, C. C., and Leonard, K. J. 1985. A modification of Gregory's model for describing plant disease gradients. Phytopathology 75:930-935.

50. Payandeh, B., Wallace, D. R., and MacLeod, D. M. 1980. An empirical regression function suitable for modelling spore germination subject to temperature threshold. Can. J. Bot. 55:936-941.

51. Pearson, R. C., Aldwinkle, H. S., and Seem, R. C. 1977. Teliospore germination and basidiospore formation in Gymnosporangium juniperi-virginianae: A regression model of temperature and time effects. Can. J. Bot. 55:2832-2837.

52. Pennypacker, S. P., Knoble, H. D., Antle, C. E., and Madden, L. V. 1980. A flexible model for studying plant disease progression. Phytopathology
70:232-235.

53. Rawlings, J. O. 1988. Applied regression analysis. Wadsworth and Brooks, Belmont, CA.

54. Rotem, J. 1978. Climatic and weather influences on epidemics. Pages 317-337 in: Plant Diseases: An Advanced Treatise, vol. 2. J. G. Horsfall and E. B. Cowling, eds. Academic Press, London.

55. Rotem, J., Cohen, Y., and Putter, J. 1971. Relativity of limiting and optimum inoculum loads, wetting durations, and temperatures for infection by Phytophthora infestans. Phytopathology 61:275-278.

56. Rouse, D. I. 1985. Construction of temporal models: I. Disease progress of airborne pathogens. Pages 11-29 in: Advances in Plant Pathology. Vol. 3, Mathematical Modelling of Crop Disease. C. A. Gilligan, ed. Academic Press, New York.

57. Scherm, H., and van Bruggen, A. H. C. 1993. Response surface models for germination and infection of Bremia lactucae, the fungus causing downy mildew of lettuce. Ecol. Model. 65:281-296.

58. Scherm, H., and van Bruggen, A. H. C. 1994. Global warming and nonlinear growth: How important are changes in average temperature? Phytopathology 84:1380-1384.

59. Schrodter, H. 1965. Methodisches zür Bearbeitung phytometeoropatholischer Unterschungen, dargestellt am Beispiel der Temperaturrelation. Phytopathol. Z. 53:154-166.

60. Schuh, W. 1991. Influence of temperature and leaf wetness period on conidial germination in vitro and infection of Cercospora kikuchii on soybean. Phytopathology 81:1315-1318.

61. Shaw, M. W. 1986. Effects of temperature and leaf wetness on Pyrenophora teres growing on barley cv. Sonja. Plant Pathol. 35:294-309.

62. Shaw, M. W. 1990. Effects of temperature, leaf wetness, and cultivar on the latent period of Mycosphaerella graminicola on winter wheat. Plant Pathol. 39:255-268.

63. Trapero-Casas, A., and Kaiser, W. J. 1992. Influence of temperature, wetness period, plant age, and inoculum concentration on infection and development of Ascochyta blight of chickpea. Phytopathology 82:589596.

64. Van der Plank, J. E. 1963. Plant Diseases: Epidemics and Control. Academic Press. New York.

65. Waggoner, P. E. 1965. Microclimate and plant disease. Annu. Rev. Phytopathol. 3:103-126.

66. Waggoner, P. E. 1986. Progress curves of foliar diseases: Their interpretation and use. Pages 3-37 in: Plant Disease Epidemiology: Population Dynamics and Management, vol. 1. K. J. Leonard and W. E. Fry, eds. Macmillan Publishing. Co., New York.

67. Waggoner, P. E., and Parlange, J. Y. 1974. Verification of a model of spore germination at variable, moderate temperatures. Phytopathology 64:1192-1196.

68. Yang, X., Madden, L., and Brazee, R. 1991. Application of the diffusion equation for modeling splash dispersal of point source pathogens. New Phytol. 118:295-301. 